\title{
Arecae pericarpium extract induces porcine lower-esophageal-sphincter contraction via muscarinic receptors
}

\author{
Shu-Leei Tey ${ }^{1,2}$, Chi-Ying Li ${ }^{3}$, Li-Wei Lin ${ }^{4}$ Li-Ching Chang ${ }^{2}$, Yea-Ling Chen ${ }^{1,2}$, Fang-Rong Chang ${ }^{3}$, \\ San-Nan Yang ${ }^{1,2}$ and Ching-Chung Tsai ${ }^{1,2^{*}}$ (i)
}

\begin{abstract}
Background: Gastroesophageal reflux disease (GERD) is associated with lower esophageal sphincter (LES) incompetence. In some patients, GERD is refractory to acid reduction therapy which is the main treatment for GERD. So far, medications that can increase LES tone are few. Arecae pericarpium (A. pericarpium) is a medication in Traditional Chinese Medicine known to promote intestinal motility.
\end{abstract}

Methods: We investigated the effect of A. pericarpium extracts on porcine LES motility. In addition, we used tetrodotoxin (TTX) and atropine to study the underlying mechanism of A. pericarpium extracts-induced contractions of LES.

Results: The results of this study showed that A. pericarpium extracts and their main active ingredient, arecoline, can induce the contractions of porcine LES sling and clasp muscles in a dose-response manner. TTX did not have an inhibitory effect on the contractions induced by A. pericarpium extracts and arecoline in LES. However, atropine significantly inhibited A. pericarpium extracts- and arecoline-induced contractions of LES.

Conclusion: A. pericarpium extracts can induce the contractions of porcine LES in a dose dependent manner, possibly through muscarinic receptors, and hence, may be worth developing as an alternative therapy for GERD.

Keywords: Arecae pericarpium, Lower esophageal sphincter, Motility, Muscarinic receptor

\section{Background}

Gastroesophageal reflux disease (GERD) is a disorder involving inflammation of the lower esophagus which is mainly induced by food, bile, or acid regurgitation. Incompetence of the lower esophageal sphincter (LES), including decreased tone or repeated transient relaxation, is considered a major contributing factor to GERD $[1,2]$. Up to $30 \%$ of patients show obstinate symptoms despite the use of proton pump inhibitors (PPIs), which reduce esophageal acid exposure [3]. This is partly due to

\footnotetext{
*Correspondence: u101130@gmail.com

${ }^{1}$ Department of Pediatrics, E-Da Hospital, No.1, Yi-Da Road, Yan-Chao

District, Kaohsiung City 82445, Taiwan, R.O.C.

Full list of author information is available at the end of the article
}

the importance of LES incompetence in GERD. Presently, there are limited drug choices for the treatment of LES incompetence. Baclofen is one of the few drugs that can increase LES tone; however, due to multiple neurological side effects, the clinical application of baclofen in GERD is not feasible $[4,5]$.

Arecae pericarpium (A. pericarpium) is the dried pericarp of Areca catechu L. that is common in Southern China, India, Philippines, Taiwan, and Southeast Asian countries. The unripe fruit of Areca catechu L. is harvested from winter to spring, dried after cooking, and longitudinally split into two petals. Afterwards, the pericarp is peeled to obtain A. pericarpium, a medication in Traditional Chinese Medicine (TCM) embodied in Taiwan Herbal Pharmacopeia [6]. In accordance with 
the Compendium of Materia Medica, A. pericarpium has been used to treat constipation, abdominal distension, and edema in TCM. A. pericarpium has effect on gastric emptying and can promote the function of the small intestine in rats via muscarinic receptor $[7,8]$. In addition, $A$. pericarpium can protect hepatic injury induced by alpha-naphthylisothiocyanate [9]. The use of A. pericarpium is considered safe and only very rare case experienced an allergic reaction after consumption. Furthermore, common dosage of $A$. pericarpium is $3-10 \mathrm{~g}$ [10].

To the best of our knowledge, there has been no study on the effect of $A$. pericarpium extracts on porcine LES motility to date. The aim of this study was to investigate the effect of $A$. pericarpium extracts on LES and the mechanism underlying A. pericarpium extracts-induced contractions of LES by using porcine LES.

\section{Methods}

\section{Materials}

This study was conducted in accordance with applicable laws and regulations of Taiwan, and E-Da hospital. All pigs weighed approximately $110 \mathrm{~kg}$ and were stunned with an electric shock device at $220 \mathrm{~V}$ for at least $3 \mathrm{~s}$, followed by cutting off the main artery within $15 \mathrm{~s}$ of stunning, and exsanguination until death. All pigs were slaughtered in a regulated slaughterhouse supervised by the Council of Agriculture, Executive Yuan, R.O.C. (Taiwan). The stomachs and lower esophagi of pigs were purchased from this slaughterhouse in Kaohsiung City. The subjects were exempted from the review of Institutional Animal Care and Use Committee of E-DA Hospital because the esophagi and stomachs of pigs are considered pork variety meats and not live animal parts. After proximal stomachs and distal esophagi were obtained, they were delivered in an ice-cold oxygenated Kreb-Henseleit solution to the laboratory in $30 \mathrm{~min}$. The Kreb-Henseleit buffer solution was composed of the following: $25 \mathrm{mM}$ $\mathrm{NaHCO}_{3}, 1.2 \mathrm{mM} \mathrm{NaH}_{2} \mathrm{PO}_{4}, 4.7 \mathrm{mM} \mathrm{KCl}, 118 \mathrm{mM} \mathrm{NaCl}$, $1.8 \mathrm{mM} \mathrm{CaCl}_{2}$, and $14 \mathrm{mM}$ glucose, and was kept under constant $\mathrm{pH}$ of 7.4. The tetrodotoxin (TTX) was purchased from Tocris Cookson Inc. (Avonmouth, Bristol, $\mathrm{UK})$, and arecoline hydrobromide and atropine were manufactured by Sigma-Aldrich (St. Louis, MO, USA).

\section{Preparation of $A$. pericarpium extracts}

A. pericarpium was purchased from Da-Tian Chinese Medicine pharmacy (Kaohsiung, Taiwan, ROC) and authenticated by Dr. Li-Wei Lin (The School of Chinese Medicine for Post-Baccalaureate, I-Shou University) according to Taiwan Herbal Pharmacopeia [6]. A herbarium sample (code number, ISU-MCMM-199) was preserved in the School of Chinese Medicine for
Post-Baccalaureate, I-Shou University (Kaohsiung, Taiwan, $\mathrm{ROC}$ ) for future reference. Dried $A$. pericarpium $(30 \mathrm{~g})$ was chopped and soaked in $300 \mathrm{ml}$ of $95 \%$ ethanol for $24 \mathrm{~h}$ and the mixture was filtered with gauze. The resulting filtrate is referred to as extract 1 of $A$. pericarpium. Residual $A$. pericarpium was soaked and filtered repeatedly in the same way as described above, to produce extracts 2 and 3 , respectively. Additionally, $1 \mathrm{~g}$ of $A$. pericarpium was powdered, soaked in $20 \mathrm{~mL}$ of $95 \%$ ethanol, vortexed using ultrasonic power $200 \mathrm{~W}$ at $30^{\circ} \mathrm{C}$ for $1 \mathrm{~h}$, and the resulting solution filtered to produce extract 4 . These extracts were concentrated under vacuum with a rotary evaporator to produce around $30 \mathrm{ml}$ of dense plasters, and the plasters were then freeze-dried $[11,12]$.

\section{High performance liquid chromatography (HPLC) analysis of arecoline in A. pericarpium extracts}

The chromatographic system consisted of a Shimadzu SIL-10AD VP auto injector, a Shimadzu LC-20AD prominence liquid chromatography and a Shimadzu SPD-M10A VP diode array detector (Shimadzu, Kyoto, Japan). A Cosmosil 5C18-PAQ $4.6 \mathrm{~mm} \times 250 \mathrm{~mm}$ column (Nacalai tesque, CA, USA) was used for the separation and the temperature was controlled at $30^{\circ} \mathrm{C}$. The mobile phase consisted of $0.5 \%$ aqueous phosphoric acid and $99.5 \%$ acetonitrile at volumetric ratios. The detection was monitored at $215 \mathrm{~nm}$. The mobile phase was delivered at a rate of $1.0 \mathrm{~mL} / \mathrm{min}$ and the volume of injection loop was $10 \mu \mathrm{L}$. According to Taiwan Herbal Pharmacopeia, arecoline is the active ingredient of Areca catechu L. [6]. Arecoline $(1 \mathrm{mg} / \mathrm{mL})$ was diluted to $0.4,0.2,0.1,0.05,0.025$, and $0.01 \mathrm{X}$ and analyzed using HPLC. We also dissolved $1 \mathrm{mg}$ powder of extracts of $A$. pericarpium in $1 \mathrm{ml}$ of $10 \%$ ethanol for HPLC analysis. The extraction yield of arecoline from $A$. pericarpium was calculated as

Extraction yield $(w / w)=\frac{\text { Mass of arecoline (in extracted solution) }}{\text { Mass of material A.pericarpium }} \times 100 \%$

\section{Measurement of $A$. pericarpium extracts-induced contractions of porcine LES}

In contrast to the circular LES of rats, pigs share similar anatomy of LES with humans as they are both composed of sling and clasp muscles [13]. For this reason, swine LES is commonly used for the study of human gastroesophageal reflux and esophageal motility disorder [14-17]. According to previously reported method, one end of the muscle strips was attached to an isometric transducer with surgical wire (FORT10g; Grass Technologies, RI, USA). The transducer was connected to an amplifier (Gould Instrument Systems, OH, USA), the signal obtained was then recorded by a computer 
recording system (BIOPAC Systems, CA, USA) [16, 17]. The muscle's basal tone was set to $1.0 \mathrm{~g}$ for this study. After a 30 -min equilibration period, $1 \times 10^{-6} \mathrm{M}$ carbachol was added to the organ bath to induce contraction of the muscle strip, and the carbachol was washed away. One mg powders from extracts 1 and 2 respectively were used and dissolved in $1 \mathrm{ml} \mathrm{10 \%} \mathrm{ethanol} \mathrm{in} \mathrm{order} \mathrm{to} \mathrm{check}$ the effect of $A$. pericarpium extracts on LES. One hundred $\mu \mathrm{L}(=100 \mathrm{ng} / \mathrm{L})$ of extract 1 of $A$. pericarpium was added after another 30-min equilibration period, and $200 \mu \mathrm{L}(=200 \mathrm{ng} / \mathrm{L})$ of extract 1 of $A$. pericarpium was added (cumulative dose $=300 \mathrm{ng} / \mathrm{L}$ ) when the contraction reached a peak equilibration induced by $100 \mu \mathrm{L}$ of extract 1 of $A$. pericarpium. In the same way, the extract 2 of $A$. pericarpium was also used to check its effect on LES.

\section{Measurement of arecoline-induced contractions of porcine LES}

In order to check the effect of arecoline on LES, $300 \mathrm{nM}$ arecoline was added after a 30-min equilibration period, and $1 \mu \mathrm{M}$ arecoline was added when the contraction reaches a peak equilibration induced by $300 \mathrm{nM}$ arecoline.

\section{Effect of TTX on A. pericarpium extracts-} and arecoline-induced contractions of porcine LES To investigate the mechanism of $A$. pericarpium extracts- and arecoline-induced contractions of LES, the isolated LES was pretreated with TTX $\left(10^{-6} \mathrm{M}\right)$ into the organ bath. After $15 \mathrm{~min}, A$. pericarpium extract $(100 \mathrm{ng} / \mathrm{L}$ and $200 \mathrm{ng} / \mathrm{L})$ or arecoline $(300 \mathrm{nM}$ and $1 \mu \mathrm{M})$ was added sequentially to the organ bath as earlier described $[16,18]$.

\section{Effect of atropine on A. pericarpium extracts-} and arecoline-induced contractions of porcine LES To investigate the mechanism of $A$. pericarpium extracts- and arecoline-induced contractions of LES, the isolated LES was also pre-treated with atropine $\left(10^{-6} \mathrm{M}\right)$, for $6 \mathrm{~min}$ followed by the addition of $A$. pericarpium extract $(100 \mathrm{ng} / \mathrm{L}$ and $200 \mathrm{ng} / \mathrm{L})$ or arecoline (300 $\mathrm{nM}$ and $1 \mu \mathrm{M}$ ) sequentially to the organ bath as earlier described $[16,18]$.

\section{Data analysis}

The data are expressed as the means \pm SEM. Statistical analysis of the results was performed by using MannWhitney $\mathrm{U}$ test. The minimum sample size was 4 . In all cases, differences were considered significant at $p<0.05$. All analyses were performed using the SPSS statistical software version 24 (IBM Corp., NY, USA).

\section{Results}

HPLC analysis of arecoline in A. pericarpium extracts

The chromatogram of the standard compound arecoline and that of the extracts of $A$. pericarpium is shown in Fig. $1 \mathrm{~A}$ and $\mathrm{B}$, respectively. The sample calibration curve for arecoline was linear $\left(r^{2}=0.9982\right)$ within the range $0-50 \mathrm{mg} / \mathrm{mL}$. Intra- and inter-day coefficients of variation of the assays were less than $5 \%(n=5)$. The content of arecoline was detected by HPLC and quantified as 1.3, $0.6,0.3$ and $2.0 \mu \mathrm{g} / \mathrm{mL}$ in extracts $1,2,3$, and 4 of $A$. pericarpium, respectively. Furthermore, because 0.47, 0.57, 0.81 and $0.16 \mathrm{~g}$ powders were obtained from extracts 1 , 2,3 , and 4 , respectively, the extraction yield of arecoline from $A$. pericarpium was $0.02,0.011,0.011$, and $0.32 \%$ in extracts $1,2,3$, and 4 , respectively.

\section{Measurement of $A$. pericarpium extracts-induced contractions of porcine LES}

Figure 2A shows typical tracings of $A$. pericarpium extractsinduced tonic contractions of sling and clasp muscles. Contractile responses were produced in sling and clasp muscles by the application of increasing dosages of $A$. pericarpium extracts. As shown in Fig. 2B, cumulative doses of 100 and $300 \mathrm{ng} / \mathrm{L}$ of extract 1 of $A$. pericarpium caused significant contractile responses of $66.19 \pm 5.44 \%$ and $92.71 \pm 6.61 \%$ while extract 2 caused $34.54 \pm 5.79 \%$ and $59.43 \pm 7.43 \%$ responses to $1 \mu \mathrm{M}$ carbachol-induced contractions in sling muscles, respectively. There was a significant difference between the two contractions induced by different volumes of either extract 1 or 2 ( $p=0.02$ and 0.04 respectively, both $n=4)$. In addition, cumulative doses of 100 and $300 \mathrm{ng} / \mathrm{L}$ of $A$. pericarpium extract 1 caused significant contractions of $27.72 \pm 3.18 \%$ and $54.30 \pm 4.09 \%$ while extract 2 caused $15.69 \pm 3.36 \%$ and $33.90 \pm 2.32 \%$ responses to $1 \mu \mathrm{M}$ carbachol-induced contractions in clasp muscles, respectively. Cumulative dose of $300 \mathrm{ng} / \mathrm{L}$ of either extract 1 or 2 induced an increased significantly contractions than $100 \mathrm{ng} / \mathrm{L}$ respectively ( $p=0.002$ and 0.005 respectively, both $n=4)$.

\section{Measurement of arecoline-induced contractions of porcine LES}

Figure 2A shows typical tracings of arecoline-induced tonic contractions of sling and clasp muscles. As shown in Fig. $2 \mathrm{C}$, the contractile responses of LES with cumulative doses of $300 \mathrm{nM}$ and $1 \mu \mathrm{M}$ arecoline were $43.82 \pm 7.91 \%$ and $85.94 \pm 7.58 \%$ while $39.41 \pm 4.81 \%$ and $80.15 \pm 5.92 \%$ contractions was induced by $1 \mu \mathrm{M}$ carbachol in the sling and clasp muscles, respectively. There was a significant difference between the two contractions induced by $300 \mathrm{nM}$ and $1 \mu \mathrm{M}$ arecoline in LES sling and clasp muscles ( $p=0.002$ and $0.0002, n=4$ and 7 respectively). 


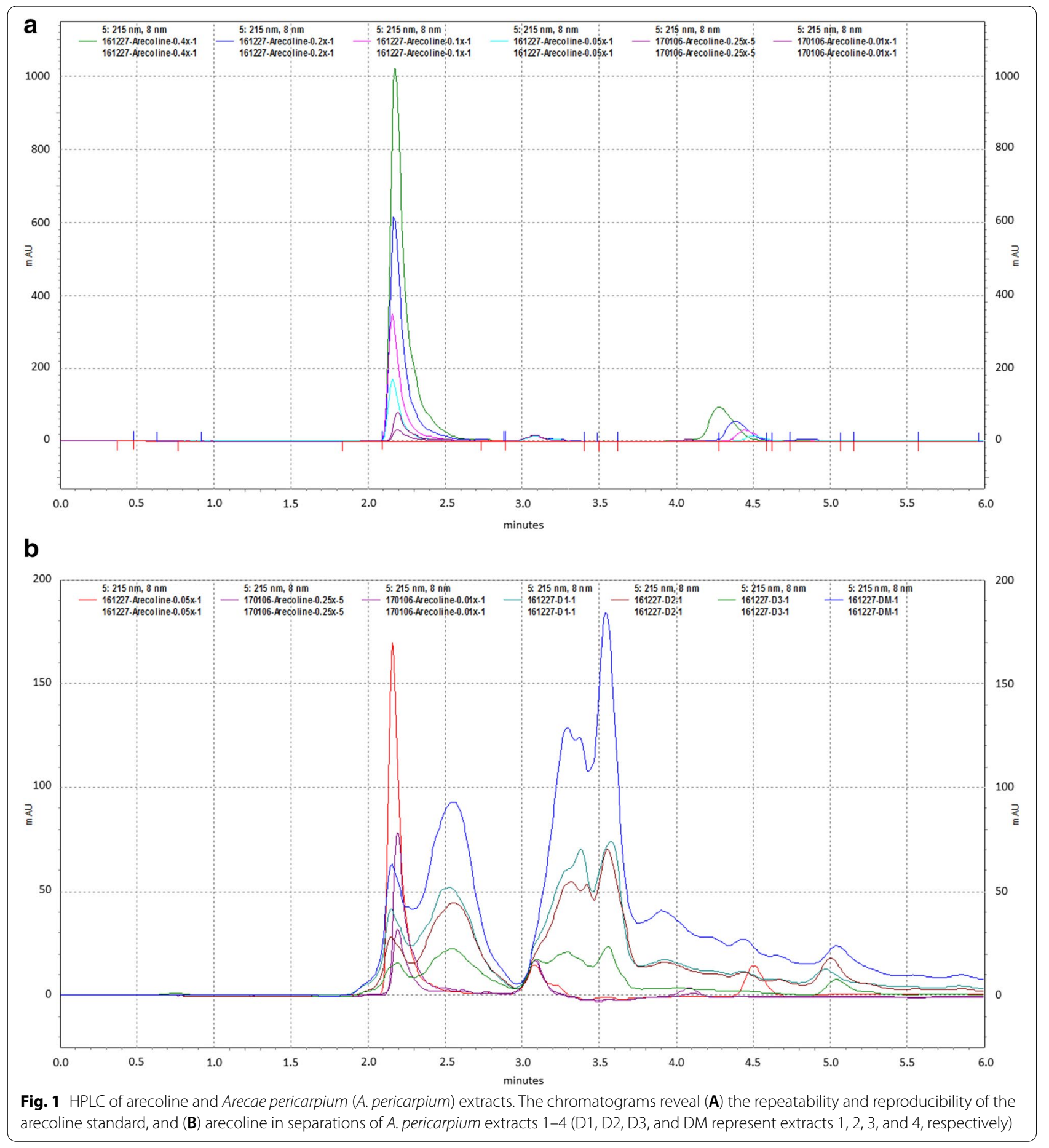

Effect of TTX on A. pericarpium extractsand arecoline-induced contractions of porcine LES As shown in Fig. 3A, the dose-response contractions of $A$. pericarpium extracts were almost unaffected by pretreatment with TTX $(p>0.05$, compared to the corresponding $A$. pericarpium extracts alone, $\mathrm{n}=4$ ). In addition, the effect of TTX on arecoline-induced contractions of LES sling and clasp muscles was not significant, compared to arecoline alone in Fig. 3B $(p>0.05$, $n \geq 4$ ). 
Thy et al. BMC Complement Med Sher

(2021) 21:275

Page 5 of 9

a sling

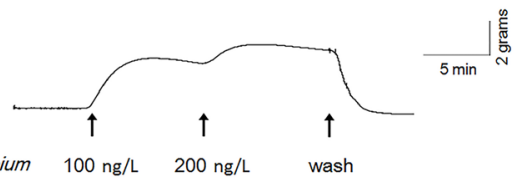

Extract 1 of Areca pericarpium
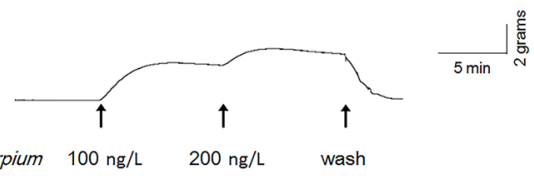

Extract 2 of Arecae pericarpium

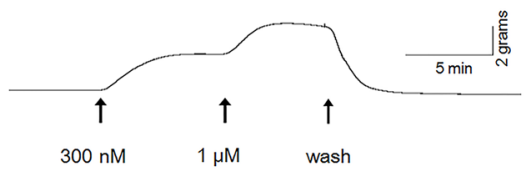

b

Aercoline

$1 \mu \mathrm{M}$

$\rightarrow$ Extrad 1 of Arecas pericardium sling

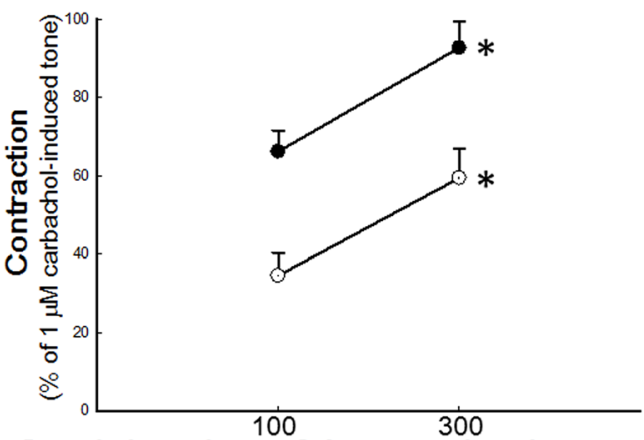

Cumulative volume of Areca pericardium extracts (ng/L)

C

sling

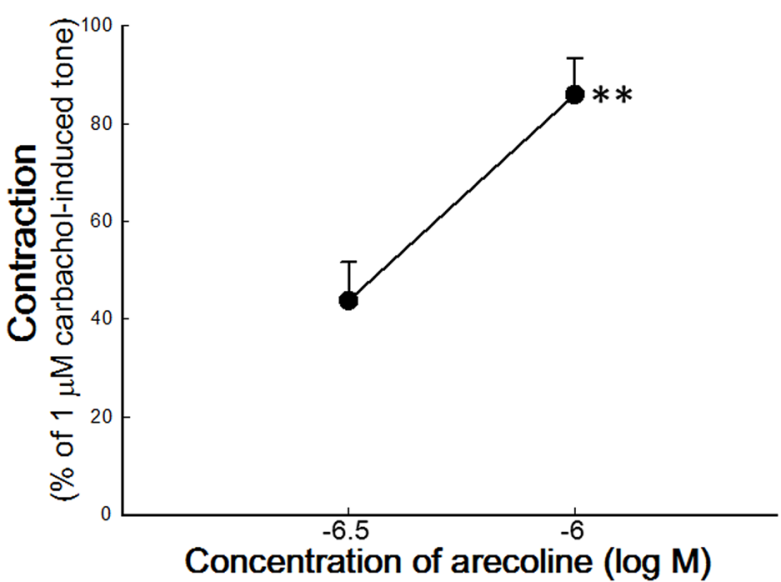

Aercoline

clasp

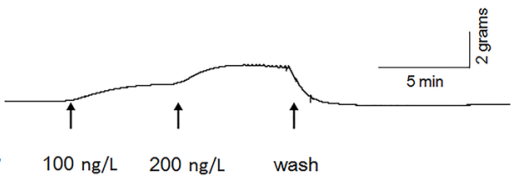

Extract 1 of Arecas pericarpium

wash

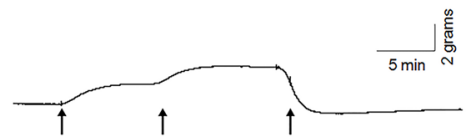

Extract 2 of Arecae pericarpium

$100 \mathrm{ng} / \mathrm{L} \quad 200 \mathrm{ng} / \mathrm{L}$

wash

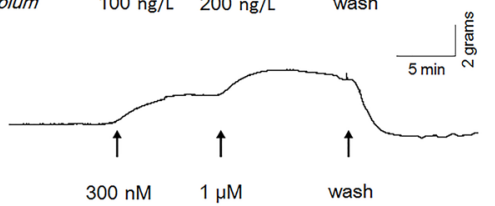

- Extract 1 of Arecas pericardium
- - Extract 2 of Arecas pericardium clasp

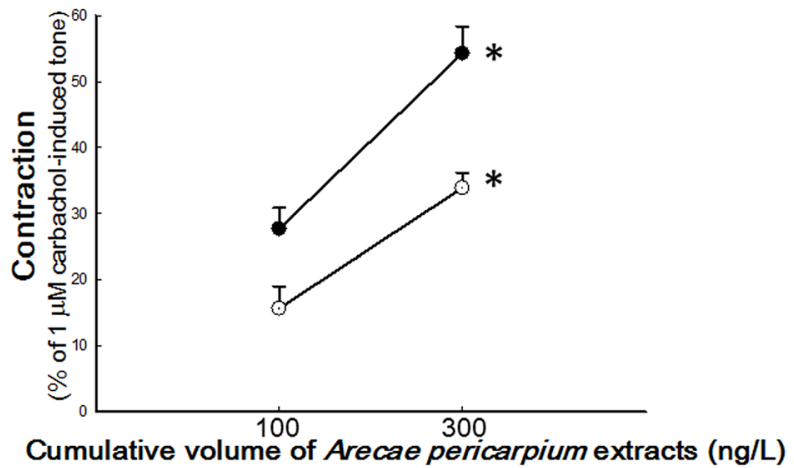

clasp

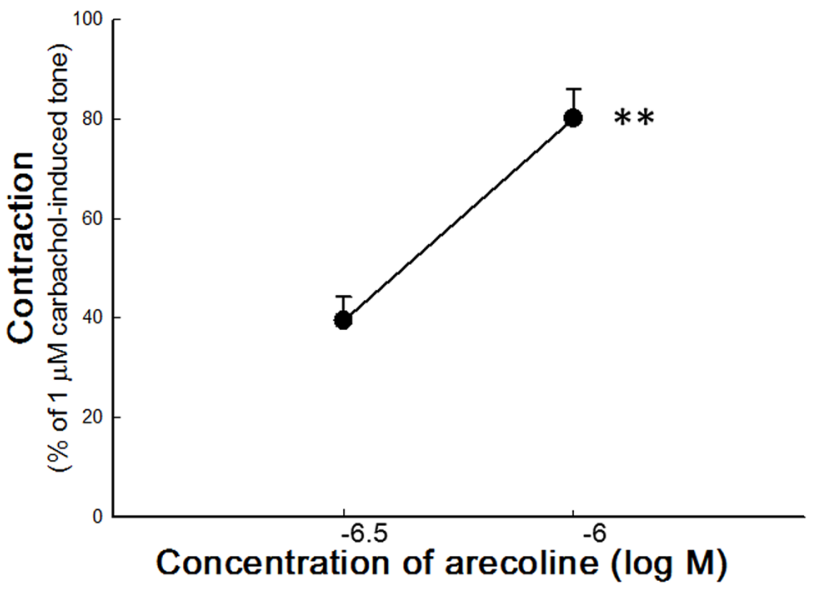

Concentration of arecoline $(\log M)$

Fig. 2 The Arecas pericarpium (A. pericarpium) extracts- and arecoline-induced contractions of porcine lower esophageal sphincters (LES). A Typical tracing of the contractions of porcine LES sling and clasp muscles in response to cumulative addition of $A$. pericarpium extracts and arecoline. Arrows indicate the addition of $A$. pericarpium extracts to LES as cumulative dosage. Dose-response curves of (B) extracts 1 and 2 of $A$. pericarpium-induced $(n=4)$ or $(\mathbf{C})$ arecoline-induced $(n \geq 4)$ contractions of porcine sling and clasp muscles. ${ }^{*}$,* represent significant differences $(p<0.05)$ from the response caused by $100 \mathrm{ng} / \mathrm{L}$ corresponding A. pericarpium extract or $300 \mathrm{nM}$ arecoline, respectively 


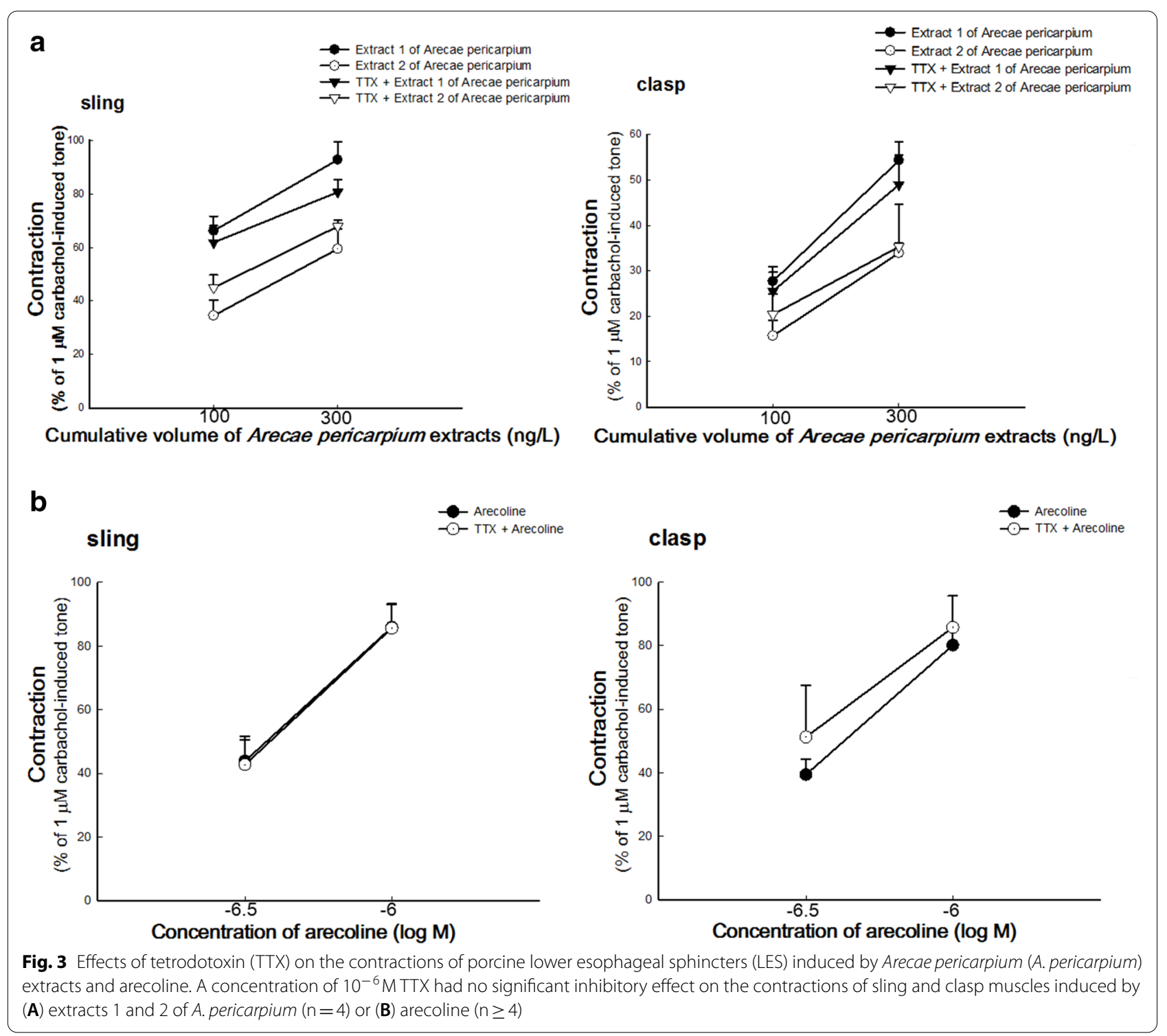

Effect of atropine on A. pericarpium extracts-

\section{and arecoline-induced contractions of porcine LES}

As shown in Fig. 4A, pretreatment with atropine had a significant inhibitory effect on $A$. pericarpium extractsinduced contractions of LES ( $p=0.001(100 \mathrm{ng} / \mathrm{L})$ and $0.0007(300 \mathrm{ng} / \mathrm{L})$ in sling muscles and $0.009(100 \mathrm{ng} / \mathrm{L})$ and $0.004(300 \mathrm{ng} / \mathrm{L})$ in clasp muscles, compared to $A$. pericarpium extracts alone, all $n=4)$. In addition, a significant inhibitory effect of atropine on arecolineinduced contractions of LES sling and clasp muscles was also observed, compared to arecoline alone as shown in Fig. 4B ( $p=0.005(300 \mathrm{nM})$ and $0.0003(1 \mu \mathrm{M})$ in sling muscles and $0.0001(300 \mathrm{nM})$ and 0.00001 $(1 \mu \mathrm{M})$ in clasp muscles, $\mathrm{n}=4$ and 7 in sling and clasp muscles respectively).

\section{Discussion}

These results reveal that $A$. pericarpium extracts and their main active ingredient, arecoline, caused the contractions of porcine LES sling and clasp muscles in a dose-response manner. In addition, LES contraction curves induced by $A$. pericarpium extracts and arecoline returned to the prestimulation levels after the removal of $A$. pericarpium extracts or arecoline, suggesting that these contractile effects probably did not occur via toxic effects.

Excitatory postganglionic myenteric neurons in the LES may release acetylcholine and its derivatives, which activate muscarinic receptors, thereby causing an increase in cytosolic $\left[\mathrm{Ca}^{2+}\right]$ [19]. In addition, the activation of $\mathrm{Ca}^{2+}$ channels facilitates extracellular $\mathrm{Ca}^{2+}$ influx 


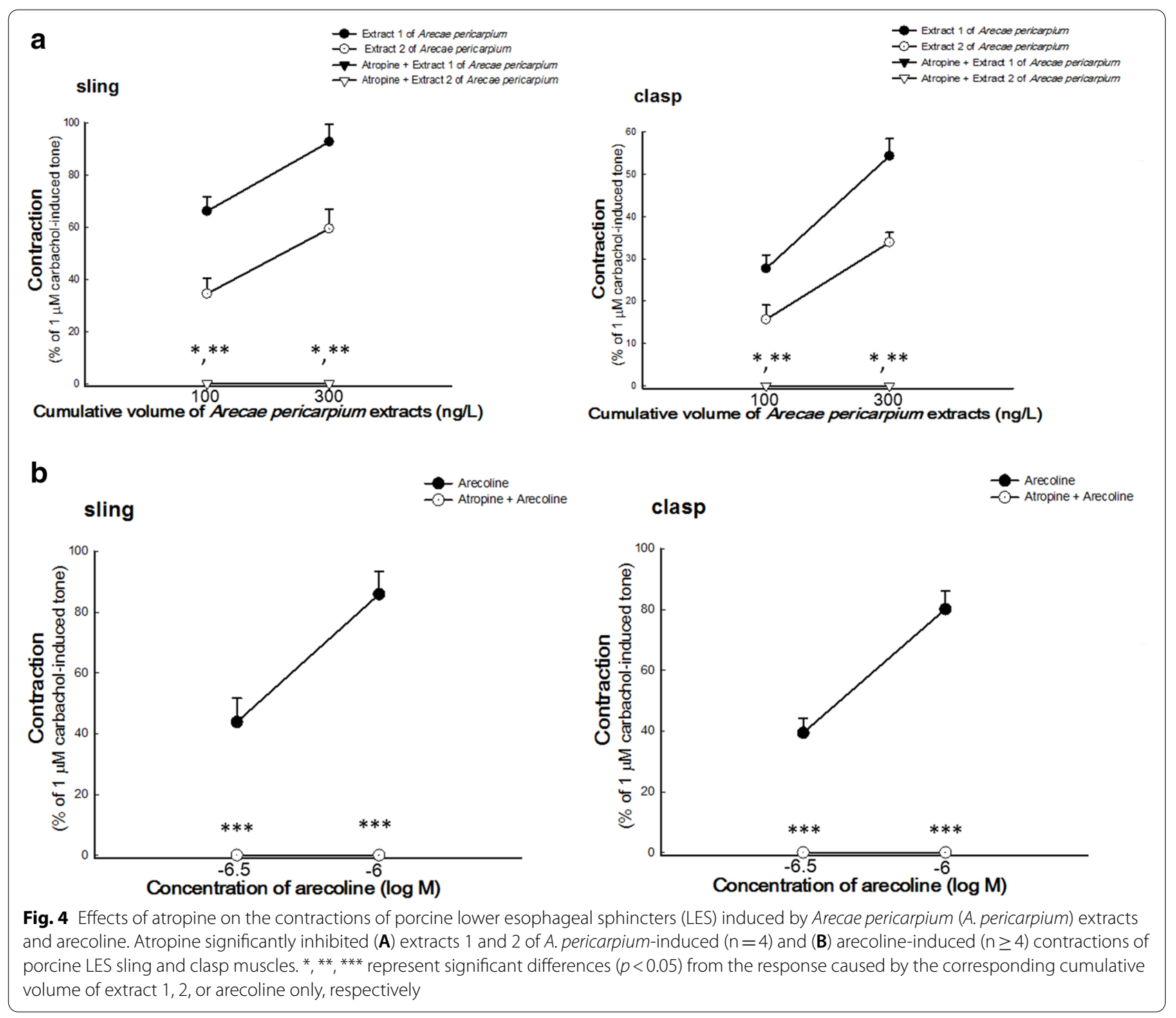

into cells, thereby increasing cytosolic $\left[\mathrm{Ca}^{2+}\right]$. Cytosolic $\mathrm{Ca}^{2+}$ binds to calmodulin, resulting in the activation of myosin light chain kinase (MLCK). MLCK phosphorylates the $20 \mathrm{kDa}$ light chain of myosin, and myosin conjugates with actin to initiate cross-bridge cycling which induces smooth muscle contraction $[20,21]$.

TTX acts as a sodium channel blocker which blocks voltage-dependent sodium channels in motor neurons. However, the contractions of LES sling and clasp muscles induced by $A$. pericarpium extracts and arecoline were not blocked by TTX in this study. This indicates that $A$. pericarpium extracts- and arecoline-induced contractions of LES were not induced by the effect of these substances on nerve fibers.
The non-selective muscarinic receptor antagonist atropine can block the muscarinic receptors $\left(\mathrm{M}_{1-5}\right)$. Atropine inhibited $A$. pericarpium extracts- and arecoline-induced contractions of LES sling and clasp muscles. These results indicate that $A$. pericarpium extracts- and arecolineinduced contractions were possibly mediated by muscarinic receptors.

Extracts from several medicinal plants, such as Ceratonia silique, Myrtus communis, Salvia miltiorrhiza, and Cydonia oblonga, have been reported to be useful for the management of GERD, in both animal and human studies. In these animal studies, the mechanisms underlying the beneficial effects of the extracts were considered to be related to anti-oxidation, anti-inflammation, 
improvement of gastric mucus and barrier function, or a reduction in gastric acid [22]. However, inducing LES contraction to avoid reflux is more helpful for patients with PPI-refractory GERD than other treatment effects. To date, only Salvia miltiorrhiza has been reported to induce tonic contraction of the LES in Sprague-Dawley rats [18]. However, the effect of $A$. pericarpium extract on porcine LES is more dominant than that of Salvia miltiorrhiza extract in rats because of the similarities between the porcine and the human LES.

Previous study demonstrated that arecoline can excite the colonic smooth muscle motility in rabbits via muscarinic receptor [23]. In addition, A. pericarpium can promote gastrointestinal motility in rats via muscarinic receptor [7, 8]. However, the LES is a specialized smooth muscle that is different from the muscularis propria of the gastrointestinal tract, because LES always remains contracted and temporarily opens only during swallowing. A key novel finding of this study is that A. pericarpium extracts and arecoline can induce contractions in this specialized smooth muscle.

Arecoline is one of several active ingredients of Areca catech $u$ L. and can cause side effects such as the promotion of oral submucosal fibrosis (OSF). However, the development of OSF takes time, and it is observed that 3.5 and 6.5 years of chewing areca nut was necessary to develop OSF in younger and older cohorts, respectively [24]. Furthermore, the half-maximal inhibitory concentration $\left(\mathrm{IC}_{50}\right)$ of arecoline was approximately $210 \mu \mathrm{M}$ in $\mathrm{HaCaT}$ keratinocytes and buccal mucosal fibroblasts (BMFs) $[25,26]$. The concentrations of arecoline used in studies on OSF were reported to be around $160 \mu \mathrm{M}$ in $\mathrm{HaCaT}$ cells and 0 to $672 \mu \mathrm{M}$ in BMFs $[27,28]$. However, in this study, the working concentration of arecoline applied to LES tissues $(300 \mathrm{nM}$ to $1 \mu \mathrm{M})$ was much lower than previously reported $\mathrm{IC}_{50}$ concentrations or those used for studying OSF. Moreover, arecoline has different effects depending on the concentration, such as increasing cell proliferation rate but inducing cell cycle arrest, apoptosis, and DNA damage at lower and higher concentrations, respectively, in oral squamous cell carcinoma cells [29]. Previous studies have focused on the relationship between the dosage and toxicity of arecoline, but it is important to determine the difference between pharmacological dosages with an appropriate effect and toxic doses of arecoline [30].

In addition, epigallocatechin-3-gallate (extracted from green tea), Ganoderma microsporum immunomodulatory protein (extracted from Ganoderma microsporum), and hinokitiol (derived from Chamacyparis taiwanensis) can suppress arecoline-induced
OSF [31-34]. These findings provide an opportunity for further research to develop a multicomponent herbal preparation that not only mitigates against unwanted side effects of arecoline but which can also be used for the management of GERD.

\section{Conclusions}

A. pericarpium extracts can induce the contractions of porcine LES in a dose dependent manner, and the contractions are possibly related to muscarinic receptors. These results suggest that $A$. pericarpium may be exploited as a potential alternative therapy for GERD.

\section{Abbreviations \\ GERD: Gastroesophageal reflux disease; PPI: Proton pump inhibitor; LES: Lower esophageal sphincters; A. pericarpium: Arecae pericarpium; TCM: Traditional Chinese Medicine; HPLC: High performance liquid chromatography; MLCK: Myosin light chain kinase; TTX: Tetrodotoxin; $I_{50}$ : Half-maximal inhibitory concentration.}

\section{Acknowledgements}

The authors thanks Ph.D. Shih-Che Huang for helpful suggestions and technical consultation.

\section{Authors' contributions}

CCT and LWL conceived the idea of this study. LWL and LCC performed extraction. SLT, CYL and FRC conducted HPLC. CCT, YLC and SLT performed ex vivo muscular experiments. SNY, CCT and LCC analyzed the data. CCT and SLT wrote the paper. CCT revised the manuscript. All authors read and approved the final manuscript.

\section{Funding}

This study was supported by intramural funding, provided by the E-Da hospital (EDAHP105031, EDAHP106072, EDAHI107004, and EDAHP107042). The funding body had no role in the design of the study or collection, analysis, and interpretation of data and in writing the manuscript.

\section{Availability of data and materials}

All relevant data are included within the manuscript and are available from the corresponding author on reasonable request.

\section{Declarations}

Ethics approval and consent to participate

The study was exempted from the review of Institutional Animal Care and Use Committee of E-DA Hospital because the study didn't involve live animals.

\section{Consent for publication}

All authors read and approved the final manuscript.

\section{Competing interests}

The authors declare no conflict of interest or competing financial interests.

\section{Author details}

${ }^{1}$ Department of Pediatrics, E-Da Hospital, No.1, Yi-Da Road, Yan-Chao District, Kaohsiung City 82445, Taiwan, R.O.C.. ${ }^{2}$ School of Medicine, I-Shou University, No. 8, Yi-Da Road, Yan-Chao District, Kaohsiung City 82445, Taiwan, R.O.C.. ${ }^{3}$ Graduate Institute of Natural Products, College of Pharmacy, Kaohsiung Medical University, No.100, Shih-Chuan 1st Road, Sanmin District, Kaohsiung City 80708, Taiwan, R.O.C.. ${ }^{4}$ School of Chinese Medicine for Post Baccalaureate, I-Shou University, No.8, Yi-Da Road, Yan-Chao District, Kaohsiung City 82445 , Taiwan, R.O.C. 
Received: 14 March 2020 Accepted: 4 August 2021

Published online: 04 November 2021

\section{References}

1. Mittal R, Vaezi MF. Esophageal motility disorders and gastroesophageal reflux disease. N Engl J Med. 2020;383:1961-72.

2. Fuchs KH, DeMeester TR, Otte F, Broderick RC, Breithaupt W, Varga $\mathrm{G}$, et al. Severity of GERD and disease progression. Dis Esophagus. 2021:34:doab006. https://doi.org/10.1093/dote/doab006.

3. Naik RD, Meyers MH, Vaezi MF. Treatment of refractory gastroesophageal reflux disease. Gastroenterol Hepatol (NY). 2020;16:196-205.

4. Roman S, Mion F. Refractory GERD, beyond proton pump inhibitors. Curr Opin Pharmacol. 2018:43:99-103.

5. Clarke JO, Fernandez-Becker NQ, Regalia KA, Triadafilopoulos G. Baclofen and gastroesophageal reflux disease: seeing the forest through the trees. Clin Transl Gastroenterol. 2018:9:137.

6. Taiwan Herbal Pharmacopeia. Taiwan Herbal Pharmacopeia 2nd edition English version. Taipei: Ministry of health and welfare; 2016. p. 28-9.

7. Li Y. Foundation and clinical research on the effect of traditional Chinese herbs on gastrointestinal motility. Chin J Integr Med. 2009:15:86-8.

8. Wang HL, Li Y, Bai H, Zhang J. Effect of qi-regulating Chinese medicine on gastrointestinal motility. World J Dig. 2004;12:1136-8 [In Chinese, English abstract]

9. Ohta S, Sato N, Tu SH, Shinoda M. Protective effects of Taiwan crude drugs on experimental liver injuries. Yakugaku Zasshi. 1993;113:870-80 [In Japanese, English abstract].

10. Wang W, Xu L. Herbs for regulating Qi: Da Fu Pi. In: Chinese Materia Medica: Combinations and Applications. Potters Bar: Donica; 2002. p. 288.

11. Tsai MH, Huang GS, Hung YC, Bin L, Liao LT, Lin LW. Psoralea corylifolia extract ameliorates experimental osteoporosis in ovariectomized rats. Am J Chin Med. 2007:35:669-80.

12. Dechayont B, Phuaklee P, Chunthorng-Orn J, Juckmeta T, Prajuabjinda O, Jiraratsatit K. Antibacterial, anti-inflammatory and antioxidant activities of Mahanintangtong and its constituent herbs, a formula used in Thai traditional medicine for treating pharyngitis. BMC Complement Med Ther. 2021;21:105

13. Farré $R$, Aulí $M$, Lecea $B$, Estrada $O$, Suñol X, Clavé P. Mechanisms controlling function in the clasp and sling regions of porcine lower oesophageal sphincter. Br J Surg. 2007;94:1427-36.

14. Korn O, Stein HJ, Richter TH, Liebermann-Meffert D. Gastroesophageal sphincter: a model. Dis Esophagus. 1997;10:105-9.

15. Schopf BW, Blair G, Dong S, Troger KA. A porcine model of gastroesophageal reflux. J Investig Surg. 1997;10:105-14.

16. Tsai CC, Chang LC, Lin KJ, Tey SL, Su YT, Liu CW, et al. Mechanism of bombesin-induced tonic contraction of the porcine lower esophageal sphincter. Sci Rep. 2015;5:15879.

17. Tsai CC, Tey SL, Chang LC, Su YT, Lin KJ, Huang SC. Estradiol mediates relaxation of porcine lower esophageal sphincter. Steroids. 2018;136:56-62.

18. Tsai CC, Chang LC, Huang SC, Tey SL, Hsu WL, Su YT, et al. Salvia miltiorrhiza induces tonic contraction of the lower esophageal sphincter in rats via activation of extracellular Ca ${ }^{2+}$ influx. Molecules. 2015;20:14504-21.
19. Hornby PJ, Abrahams TP. Central control of lower esophageal sphincter relaxation. Am J Med. 2000;108:90S-8S.

20. Sanders KM. Regulation of smooth muscle excitation and contraction. Neurogastroenterol Motil. 2008;20 Suppl: 1:39-53.

21. Perrino BA. Calcium sensitization mechanisms in gastrointestinal smooth muscles. J Neurogastroenterol Motil. 2016;22:213-25

22. Salehi M, Karegar-Borzi H, Karimi M, Rahimi R. Medicinal plants for Management of Gastroesophageal Reflux Disease: a review of animal and human studies. J Altern Complement Med. 2017:23:82-95.

23. Xie DP, Chen LB, Liu CY, Zhang CL, Liu KJ, Wang PS. Arecoline excites the colonic smooth muscle motility via M3 receptor in rabbits. Chin J Physiol. 2004:47:89-94.

24. Ranganathan K, Devi MU, Joshua E, Kirankumar K, Saraswathi TR. Oral submucous fibrosis: a case-control study in Chennai, South India. J Oral Pathol Med. 2004;33:274-7.

25. Li L, Gu L, Yao Z, Wang Y, Tang Z, Wu X. Arecoline suppresses epithelial cell viability by upregulating tropomyosin-1 through the transforming growth factor- $\beta / S m a d$ pathway. Pharm Biol. 2020;58:1244-51.

26. Adtani PN, Narasimhan M, Punnoose AM, Kambalachenu HR. Antifibrotic effect of Centella asiatica Linn and asiatic acid on arecoline-induced fibrosis in human buccal fibroblasts. J Investig Clin Dent. 2017;8. https:// doi.org/10.1111/jicd.12208.

27. Lee SS, Chen YJ, Tsai CH, Huang FM, Chang YC. Elevated transglutaminase-2 expression mediates fibrosis in areca quid chewing-associated oral submucocal fibrosis via reactive oxygen species generation. Clin Oral Investig. 2016;20:1029-34

28. Tsai CH, Lee SS, Chang YC. Hypoxic regulation of plasminogen activator inhibitor-1 expression in human buccal mucosa fibroblasts stimulated with arecoline. J Oral Pathol Med. 2015:44:669-73.

29. Tu HF, Chen MY, Lai JC, et al. Arecoline-regulated ataxia telangiectasia mutated expression level in oral cancer progression. Head Neck. 2019:41:2525-37.

30. Shen YW, Shih YH, Fuh LJ, Shieh TM. Oral submucous fibrosis: a review on biomarkers, pathogenic mechanisms, and treatments. Int J Mol Sci. 2020;21:7231.

31. Hsieh YP, Chen HM, Chang JZ, Chiang CP, Deng YT, Kuo MY. Arecoline stimulated early growth response-1 production in human buccal fibroblasts: suppression by epigallocatechin-3-gallate. Head Neck. 2015;37:493-7

32. Chu C, Deng J, Man Y, Qu Y. Green tea extracts Epigallocatechin-3-gallate for different treatments. Biomed Res Int. 2017;2017:5615647.

33. Lee $\mathrm{PH}$, Hsieh $\mathrm{PL}$, Liao YW, Yu CC. Inhibitory effect of GMI, an immunomodulatory protein from Ganoderma microsporum, on myofibroblast activity and proinflammatory cytokines in human fibrotic buccal mucosal fibroblasts. Environ Toxicol. 2018;33:32-40.

34. Yang HW, Lu MY, Chiu YW, Liao YW, Huang YF, Ju Chueh P, et al. Hinokitiol ablates myofibroblast activation in precancerous oral submucous fibrosis by targeting snail. Environ Toxicol. 2018;33:454-62.

\section{Publisher's Note}

Springer Nature remains neutral with regard to jurisdictional claims in published maps and institutional affiliations.

Ready to submit your research? Choose BMC and benefit from

- fast, convenient online submission

- thorough peer review by experienced researchers in your field

- rapid publication on acceptance

- support for research data, including large and complex data types

- gold Open Access which fosters wider collaboration and increased citations

- maximum visibility for your research: over 100M website views per year

At BMC, research is always in progress.

Learn more biomedcentral.com/submissions 